\title{
Auto-combustion Fabrication and Optical Properties of Zinc Oxide Nanoparticles for Degradation of Reactive Red 195 and Methyl Orange Dyes
}

Ayman Awad Ali Abdelrazik ( $\sim$ ayman.abdelrazik@fsc.bu.edu.eg )

Benha University Faculty of Science https://orcid.org/0000-0002-4141-8214

Ibrahim S. Ahmed

Chemistry Department, Faculty of Science, Benha University, Benha, Egypt

Alaa S. Amin

Chemistry Department, Faculty of Science, Benha University, Benha, Egypt

Mai M. Gneidy

Chemistry Department, Faculty of Science, Benha University, Benha, Egypt

\section{Research Article}

Keywords: XRD, Zinc oxide, Photocatalytic activity, Morphology, Auto-combustion method

Posted Date: February 12th, 2021

DOI: https://doi.org/10.21203/rs.3.rs-217776/v1

License: (a) (i) This work is licensed under a Creative Commons Attribution 4.0 International License.

Read Full License

Version of Record: A version of this preprint was published at Journal of Inorganic and Organometallic Polymers and Materials on April 7th, 2021. See the published version at https://doi.org/10.1007/s10904021-01975-6. 


\section{Professor Martel Zeldin}

Editors-in-Chief of Journal of Inorganic and Organometallic Polymers and Materials

February 6, 2021

Dear Professor Martel Zeldin

We are pleased to submit the attached original research article entitled "Auto-combustion fabrication and optical properties of zinc oxide nanoparticles for degradation of reactive red 195 and methyl orange dyes" for consideration for publication as a research article Journal of Inorganic and Organometallic Polymers and Materials.

In this manuscript, zinc oxide nanoparticles were synthesized using an auto-combustion technique with fuels (tartaric acid and citric acid) according to the rule of the combustion method. the obtained zinc oxide nanoparticles were studied using various tools such XRD, DRS, TEM and FTIR. The results of XRD confirmed that the formation of the hexagonal structure of the synthesized zinc oxide after calcination at $500{ }^{\circ} \mathrm{C}$. The extracted data from XRD and TEM techniques showed that the crystallite size of the fabricated zinc oxide nanoparticles determined to be $24-39 \mathrm{~nm}$. The direct band gap, lattice parameters, unit cell volume (V), the dislocation density (D) and the Zn-O bond length (L) of the synthesized zinc oxide were determined. The values of the lattice parameters ( $\mathrm{a}$ and $\mathrm{c}$ ), the ratio (c/a), unit cell volume (V) and $\mathrm{Zn}-\mathrm{O}$ bond length (L) were determined and found in the range of 3.23333.2490 A, 5.1935-5.2081 A and 1.60251-1.60423, 47.2594-47.5458 $\mathrm{A}^{3}$ and 1.9727-1.9767 A, respectively. The calculated values are near to the standard value for hexagonal phase of zinc oxide. The synthesized zinc oxide nanoparticles are used as nanocatalyst for photodegradation of reactive red 195 and methyl orange dyes under UV light irradiation. The degradation of reactive red 195 dye was 91-94 $\%$ after 70 min over the synthesized zinc oxide and the values of degradation increased to be $99-99.8 \%$ in 50 min with $\mathrm{H}_{2} \mathrm{O}_{2}$ under UV light irradiation. Also, the degradation of methyl orange dye was 57.55$70.57 \%$ after $300 \mathrm{~min}$ over the synthesized zinc oxide (ZTA, ZCA and ZCTA samples) and the values of degradation increased to be 81-95\% in 70 min with $\mathrm{H}_{2} \mathrm{O}_{2}$ under UV light irradiation. finally, the appeared rate constant (Kapp) is determined and the mechanism of the photocatalysis process is suggested for the degradation of the dyes over the synthesized zinc oxide nanoparticles.

Manuscript is containing original research and has not been submitted/published earlier in any journal and is not being considered for publication elsewhere before a decision is made by our prestigious journal. All authors have seen and approved the manuscript and have contributed significantly for the paper. The authors agree with submission to Journal of Inorganic and Organometallic Polymers and Materials. The authors declare that they have no known competing financial interests or personal relationships that could have appeared to influence the work reported in this paper. Thank you for your consideration of our manuscript. I look forward to hearing from you.

Yours Sincerely,

Dr. Ayman Awad Ali Abdel Razik

Chemistry Department, Faculty of Science, Benha University

Fareed Nada Street, Benha, Qalubiya Governorate, Arab Republic of Egypt

Tel: +201024857536 and E-mail: ayman.abdelrazik@fsc.u.edu.eg

Signature: A. A. Ali Date: 6/2/2021 


\title{
Auto-combustion fabrication and optical properties of zinc oxide nanoparticles for degradation of reactive red 195 and methyl orange dyes
}

\author{
Ayman A. Ali*, Ibrahim S. Ahmed, Alaa S. Amin and Mai M. Gneidy \\ ${ }^{1}$ Chemistry Department, Faculty of Science, Benha University, Benha, Egypt \\ *Corresponding author: ayman.abdelrazik@fsc.bu.edu.eg
}

\begin{abstract}
A new preparation method has been successfully utilized for the fabrication of zinc oxide nanoparticles using the auto-combustion method and fuels (tartaric acid: TA and citric acid: CA) with molar ratio (Zn:TA:CA=1:1:0, 1:0:0.55 and 1:0.5:0.275). The as-fabricated ZTA, ZCA and ZCTA samples annealed at $500{ }^{\circ} \mathrm{C}$ for two hours. The calcined zinc oxide nanoparticles were investigated by various tools such as XRD, DRS, FT-IR, and HR-TEM. The average crystallite size of the fabricated zinc oxide was determined to be $24-39 \mathrm{~nm}$. The direct band gap, lattice parameters, unit cell volume (V), the dislocation density (D) and the Zn-O bond length (L) of the synthesized ZTA, ZCA and ZCTA samples were determined. The synthesized zinc oxide nanoparticles are used as nanocatalyst for photodegradation of reactive red 195 and methyl orange dyes under UV light irradiation. The degradation of reactive red 195 dye was 91-94\% after 70 min over the synthesized zinc oxide and the values of degradation increased to be $99-99.8 \%$ in 50 min with $\mathrm{H}_{2} \mathrm{O}_{2}$ under UV light irradiation. Also, the degradation of methyl orange dye was 57.55-70.57\% after $300 \mathrm{~min}$ over the synthesized zinc oxide (ZTA, ZCA and ZCTA samples) and the values of degradation increased to be $81-95 \%$ in 70 min with $\mathrm{H}_{2} \mathrm{O}_{2}$ under UV light irradiation. Finally, the appeared rate constant (Kapp) is determined and the mechanism of the photocatalysis process is suggested for the degradation of the dyes over the synthesized zinc oxide nanoparticles.
\end{abstract}

Keywords: XRD, Zinc oxide; Photocatalytic activity; Morphology; Auto-combustion method *Corresponding author: (Ayman A. Ali)

E-mail address: ayman.abderazik@fsc.bu.edu.eg

Tel.: +20 1024857536

\section{Introduction}

As a result of the global industrialization, various pollutants are produced and contaminated the water resources of our world. Wastewater produced from different industries such as printing, textile, painting, photography, drugs and leather industries and the existence of little quantity of dyes inside the water has large deleterious side effects on living things [ $\underline{1}$, 2]. Textile dyes and pharmaceutical compounds are examples of organic pollutants which 
considered the toughest pollutants to remove from aqueous media because of the chemical bonding with the water molecules. Water pollution requests some noticeable attention because it is the primary reason for the diffuse of some diseases around the world. Methyl orange and reactive red dyes are usually described by the presence of azo group and aromatic rings [ $\underline{3}, \underline{4}]$. They have complex aromatic molecular structures and they are considered very toxic to a living organism and resistant to biodegradation. In recent years, the synthesized inorganic nanomaterials, in the form of simple and composite oxides are utilized in the of inorganic and organic pollutants using photodegradation and adsorption processes [5-7].

Recently various synthesis techniques were utilized for fabrication of inorganic material

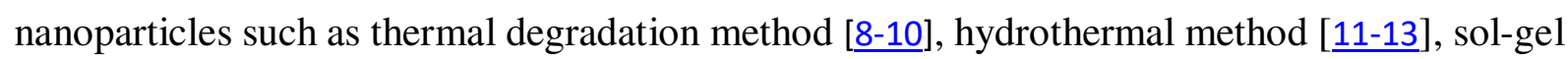
method [14-16], precipitation method [17-19], combustion synthesis [20-22], and microwave method [23-25]. Many inorganic oxides like zinc oxide, zirconium oxide, titanium oxide, stannic oxide and other oxides have considered as attractive photo-catalysts because of their high catalytic performance in the decomposition of organic materials like pesticides, dyes and detergents under sunlight and UV light irradiation [드, 26, 27]. Zinc oxide is used as a photocatalyst because it has a comparable band-gap with value $3.2 \mathrm{eV}$ which reflected the relatively large activity of zinc oxide [28-31]. It has great potential applications in room temperature such as ceramic, UV-lasers, sensors, electronics, catalysis, paint and other fields due to the chemical and physical properties like nontoxic, high chemical stabilization, low cost, good photo-electric, high surface area, small particle size, optical and electrical properties [1, 2, 32-35]. Fire combustion synthesis is recognized as low solution combustion synthesis and it used for the fabrication of simple and complex inorganic compounds [으, 22, $\underline{36-38}]$. The low combustion synthesis method is used due to easy, rapid method, save time, and cut costs of energy. It also used to synthesis pure, homogeneous, and crystalline materials.

In the current work, we pointed to synthesize zinc oxide nanoparticles by using autocombustion synthesis following by the calcination to improvement of the shape of the synthesized nanoparticles and the degree of crystallinity. The structure, optical and morphology properties of the obtained zinc oxide are well characterized by different tools such as DRS, XRD, FT-IR, and TEM. Methyl orange and reactive red 195 dyes were chosen as organic hydrocarbon dyes due to their environmental importance and the degradation and mechanism of the photocatalysis were studied using zinc oxide nanoparticles. 


\section{Experimental}

\subsection{Materials and reagents}

All chemicals used in this work were purchased and used as received without any further purification. Zinc nitrate hexahydrate $\left(\mathrm{Zn}\left(\mathrm{NO}_{3}\right)_{3} \cdot 6 \mathrm{H}_{2} \mathrm{O} ; 98 \%\right)$, reactive Red 195 dye (RR195) and methyl orange (MO) dye were purchased from Sigma-Aldrich company. Citric acid (CA: $\mathrm{C}_{6} \mathrm{H}_{8} \mathrm{O}_{7} ; 99.5 \%$ ), tartaric acid (TA: $\mathrm{C}_{4} \mathrm{H}_{6} \mathrm{O}_{6} ; 99.5 \%$ ) was purchased from El Nasr pharmaceutical chemicals company. The chemical structure and characteristics of reactive Red 195 (RR195) and methyl orange (MO) dyes are outlined in Scheme 1.

\section{Scheme 1}

\subsection{Preparation of zinc oxide nanoparticles via auto-combustion method}

0.02 mole of zinc nitrate and calculated amount of fuels were dissolved in $50 \mathrm{~mL}$ distilled water in which zinc nitrate to fuel molar ratios: 1:1, 1:0.55 and 1:0.5:0.275 for tartaric acid, citric acid, and a mixture of them (TA and CA), respectively. The oxidizing power of zinc nitrate calculated to be (-10) and the reducing power of citric and tartaric acid determined to be (18) and (10), respectively. The ratio between the fuel and zinc nitrate calculated according to the rules of the combustion method (oxidizing and reducing powers) and Eqs 1, 2 and 3. The asprepared solutions were heated with stirring at $80{ }^{\circ} \mathrm{C}$ for 10 minutes to complete the solubility. After homogenization, the solutions were heated at $120^{\circ} \mathrm{C}$ till to transform into the gel. The viscous gels were ignited on the hotplate at $250{ }^{\circ} \mathrm{C}$ until auto-ignition was finished in a few minutes, producing the black ashes and gases. The as-fabricated ashes were calcined at $500{ }^{\circ} \mathrm{C}$ for two hours and get pure zinc oxide nanoparticles. The names of products, the composition and ratio of the starting materials are summarized in Table 1.

$$
\begin{aligned}
& 9 \mathrm{Zn}\left(\mathrm{NO}_{3}\right)_{2} \cdot 6 \mathrm{H}_{2} \mathrm{O}+9 \mathrm{C}_{4} \mathrm{H}_{6} \mathrm{O}_{6} \rightarrow 9 \mathrm{ZnO}+81 \mathrm{H}_{2} \mathrm{O}+36 \mathrm{CO}_{2}+9 \mathrm{~N}_{2} \\
& 9 \mathrm{Zn}\left(\mathrm{NO}_{3}\right)_{2} \cdot 6 \mathrm{H}_{2} \mathrm{O}+5 \mathrm{C}_{6} \mathrm{H}_{8} \mathrm{O}_{7} \rightarrow 9 \mathrm{ZnO}+74 \mathrm{H}_{2} \mathrm{O}+30 \mathrm{CO}_{2}+9 \mathrm{~N}_{2} \\
& 18 \mathrm{Zn}\left(\mathrm{NO}_{3}\right)_{2} \cdot 6 \mathrm{H}_{2} \mathrm{O}+9 \mathrm{C}_{4} \mathrm{H}_{6} \mathrm{O}_{6}+5 \mathrm{C}_{6} \mathrm{H}_{8} \mathrm{O}_{7} \rightarrow 18 \mathrm{ZnO}+155 \mathrm{H}_{2} \mathrm{O}+66 \mathrm{CO}_{2}+18 \mathrm{~N}_{2}
\end{aligned}
$$

\section{Table (1)}

\subsection{Evaluation of photocatalytic studies}

$50 \mathrm{mg}$ of the synthesized zinc oxide samples (ZTA, ZCA and ZCTA) was added to 25 $\mathrm{mL}$ of dye at $\mathrm{pH} 4.2$ for reactive red and $\mathrm{pH} 5.1$ for methyl orange at room temperature with initial concentration $30 \mathrm{mg} / \mathrm{L}$. Philips UV mercury lambs (4x20 watt at $365 \mathrm{~nm}$ ) were used in the photodegradation test as the irradiation source of UV-light. The obtained suspension was magnetically stirred for a specific time. Before UV-light irradiation, the dyes solutions with catalyst were stirred in dark for one hour to attain the equilibrium between adsorption the surface 
of $\mathrm{ZnO}$ catalyst and the desorption the dye molecules on the bulk of the solution. Aliquots were withdrawn at regular duration time and centrifuged to separate zinc oxide catalyst from the dye solutions. The separated filtrates of the dye solutions were analyzed by using UV-visible spectrophotometer (Jasco; model V670). The degradation yield (D) of organic dyes over zinc oxide catalyst was given by using Eq. No. 4. Kinetic studies of the photodegradation of the testing dyes over the fabricated zinc oxide nanoparticles were investigated using first order models as shown in Eq. No. 5.

$$
\begin{aligned}
& D \%=\frac{S_{o}-S_{t}}{S_{o}} \times 100 \\
& \operatorname{Ln}\left(S_{o} / S_{t}\right)=K_{a p p} t
\end{aligned}
$$

Where, $K_{F}$ is the appeard first order constant. $S_{0}$ and $S_{t}$ are the initial concentration of the dye and the concentration of the dye after illumination for time $t$, respectively.

\subsection{Characterization}

X-ray diffraction (XRD) of the sample was obtained using diffractometer (Bruker; model $\mathrm{D} 8$ advance) with monochromatic $\mathrm{Cu}$-Ka radiation, $1.54178\left({ }^{\circ} \mathrm{A}\right)$ in the $2 \theta$ range of $15-80^{\circ}$. FTIR spectra were measured using FT-IR spectrometer (Bomem; model MB 157S) from 4000 to $400 \mathrm{~cm}^{-1}$ at room temperature. The morphology of the calcined sample was studied using a high transmission electron microscope (HR-TEM, JEOL; model $1200 \mathrm{EX}$ ) at an electron voltage of $200 \mathrm{kV}$ and Field emission scanning electron microscope (FE-SEM, JEOL: model JSM-6500F).

Diffuse reflectance of the calcined sample studied in the ultraviolet-visible (200-800 nm) using Jasco-V670 spectrophotometer and integrating sphere calibrated with the white standard as barium sulfate.

\section{Result and Discussion}

\subsection{X-ray diffraction (XRD) and structural studies}

XRD patterns of the calcined samples (ZTA, ZCA and ZCTA) are shown in Figure 1(a). The pattern shows the construction of zinc oxide nanoparticles with high crystallinity peaks in the form of Wurtzite structure (hexagonal phase with space group P63mc) and the positions of the appeared peaks of zinc oxide agree with the standard card No. 01-089-0510 and the lattice parameters are equal to $\mathrm{a}=\mathrm{b}=3.2488 \mathrm{~A}$ and $\mathrm{C}=5.2054 \mathrm{~A}$. As can be seen from Fig. 1 , the observed seven lines appeared at $2 \theta=31.79^{\circ}, 34.43^{\circ}, 36.27^{\circ}, 47.58^{\circ}, 56.63^{\circ}, 62.89^{\circ}, 66.43^{\circ}$, $67.97^{\circ}, 69.1^{\circ}, 72.64^{\circ}$ and $76.98^{\circ}$ assigned to the planes of (100), (002), (101), (102), (110), (103), (200), (112), (201), (004), (202) of hexagonal zinc oxide structure, respectively [1]]. The 
lattice parameters (a and c) were determined as shown in equation No. (7). The lattice constant ' $a$ ' is determined from Eq. No. (7) after the reducing the Eq. No. (6). Also, the lattice constant 'c' is determined from eq. No. (8) after reducing the Eq. No. (6). The crystal sizes (S) of zinc oxide determined by using the Debye-Scherrer Eq. No. (9). Also, The unit cell volume (V), the dislocation density (D) and the Zn-O bond length (L) [오, $\underline{40}]$ determined from equations No. (10), (11) and (12), respectively.

$$
\begin{aligned}
& \sin ^{2} \theta=\left(\frac{\lambda^{2}}{4 \mathrm{a}^{2}}\right)\left[\frac{\mathrm{l}^{2}}{(\mathrm{c} / \mathrm{a})^{2}}+\frac{4}{3}\left(\mathrm{~h}^{2}+\mathrm{k}^{2}+\mathrm{hk}\right)\right] \\
& \mathrm{a}=\left[\frac{\lambda}{\sqrt{3} \sin \theta}\right] \sqrt{\left(\mathrm{h}^{2}+\mathrm{k}^{2}+\mathrm{hk}\right.} \\
& \mathrm{c}=\frac{\lambda \mathrm{l}}{2 \sin \theta} \\
& \mathrm{S}=0.9 \lambda / \mathrm{W} \cos \theta \\
& \mathrm{V}=\sqrt{3} \frac{\mathrm{a}^{2} \mathrm{c}}{2} \\
& \mathrm{D}=1 / \mathrm{S}^{2} \\
& \mathrm{~L}=\sqrt{\left[\mathrm{a}^{2} / 3+\mathrm{c}^{2}((1 / 2)-\mathrm{R})^{2}\right]}
\end{aligned}
$$

Where $\lambda$ is the wavelength ( $1.5406 \mathrm{~A}$ for $\mathrm{CuK} \alpha), \theta$ is the diffraction angle and $\mathrm{W}$ is the $\mathrm{x}$-ray full width at a half-maximum height of the diffraction peak. $(h, k$ and $l)$ are miller indices, $\mathrm{a}$ and $\mathrm{b}$ are lattice parameters, $\mathrm{V}$ is unit cell volume, $\rho$ is dislocation density, $\mathrm{S}$ is the particle size in $(\mathrm{nm}), \mathrm{L}$ is the $\mathrm{Zn}-\mathrm{O}$ bond length and the value of atom displacement $(\mathrm{R})$ can be calculated from $\mathrm{R}=0.25+a^{2} /\left(3 c^{2}\right)$.

\section{Table 2}

Table 2 outlined the lattice parameters ( $\mathrm{a}$ and $\mathrm{c}$ ) of the synthesized zinc oxide (ZTA, ZCA and ZCTA samples) using Eqs. No. 6-8. The value of lattice parameter (a) was determined according to eq. No. (7) and the miller indices of the peak take the form of $(h k l)=$ (100), (110) and (200), where $l=0$. The value of lattice parameter (c) was calculated using the the miller indices of the peak in the form of $(h k l)=(002)$ and (004), where $h=k=0$ and eq. No. (8). The determined values of the lattice parameters "a" and "c" found in the range of 3.2333-3.2490 A and 5.1935-5.2081 A, respectively. The values indicate for the presence of hexagonal structure and the values are nearly to the values of the reference standard card of 
zinc oxide (Reference card: 01-089-0510 and the lattice parameters are equal to $a=b=3.2488 \mathrm{~A}$ and $\mathrm{C}=5.2054 \mathrm{~A})$.

The average crystal sizes of the calcined zinc oxide nanoparticles (ZTA, ZCA and ZCTA samples) estimated using Eq. No. (9) as shown in Table 3. The crystalline sizes (S, nm) of zinc oxide nanoparticles synthesized by tartaric acid (sample ZTA) and a mixture from tartaric acid and citric acid as fuels (sample ZCTA), are less than the obtained using citric acid fuel (sample ZCA). Table 3 summarized the values of the average lattice parameter (a and c), unit cell volume (V), dislocation density (D), the $\mathrm{Zn}-\mathrm{O}$ bond length (L) and average crystallite size of the synthesized zinc oxide. According to the average lattice constants of zinc oxide in Table 3, the ratio between $\mathrm{c}$ and $\mathrm{a}:(c / a)=1.60251-1.60423$ and the values are near to the standard value for hexagonal cell of zinc oxide $(c / a=1.633)[\underline{39}, \underline{40}]$. The values of the unit cell volume $(\mathrm{V})$ of the synthesized zinc oxide nanoparticles were found in the range of 47.2594-47.5458 $\mathrm{A}^{3}$ according to Eq. No. (10). The values of the unit cell value increase in the following order: ZCTA $>$ ZCA $>$ ZTA. The values of dislocation density (D) of the synthesized zinc oxide are calculated from Eq. No. (11) and the determined average crystallite size (nm) from Eq. No. (6). The inverse relation between the size the dislocation density as shoewn in Table 3 and it reflects that the values dislocation density increase in the following order: ZCA>ZTCA>ZTA. The Zn$\mathrm{O}$ bond length (L) can be determined using Eq. No. (12) and the values were found in the range of 1.9727-1.9767 A. It explains that the values of the $\mathrm{Zn}-\mathrm{O}$ bond length (L) increase in the following order: ZCTA> ZCA>ZTA. These values are closer to that the calculated for the bulk zinc oxide (1.9778 A) [포, $\underline{40}]$.

\section{Table 3}

\subsection{FTIR analysis}

The FT-IR spectra of the calcined zinc oxide (ZTA, ZCA and ZCTA) in the wavenumber range of $400-4000 \mathrm{~cm}^{-1}$ are shown in Figure 1(b). The absorption peaks at $3400-3450 \mathrm{~cm}^{-1}$ and $1610-1615 \mathrm{~cm}^{-1}$ are corresponding to the stretching and bending vibration mode of adsorbed water on the surface of the synthesized zinc oxide nanoparticles. The weak absorption band at $1410 \mathrm{~cm}^{-1}, 2910 \mathrm{~cm}^{-1}$ and $2850 \mathrm{~cm}^{-1}$ can be assigned to the $\mathrm{C}-\mathrm{C}$ and $\mathrm{CH}$ aliphatic groups. The characteristic absorption peak at $425-430 \mathrm{~cm}^{-1}$ indicates the stretching vibration mode of $\mathrm{Zn}-\mathrm{O}$ [33] for the synthesized samples.

Fig. 1 


\subsection{The morphology studies}

The morphology of the calcined zinc oxide in the form of Wurtzite nanoparticles was examined by high-resolution transmission electron microscopy (HR-TEM) as shown in Fig. 2(a-e). As shown in the HR-TEM, the morphology of the calcined zinc oxide sample reveals spherical and hexagonal shape with hard agglomeration. Fig. 3(f) displays the histogram graph for TEM images and the average particle size calculated from TEM-image is about $52 \mathrm{~nm}$ for ZTA sample.

Fig. 2

\subsection{Optical studies}

Figure 3(a) manifests the UV-Vis and NIR diffuse reflectance spectra of the calcined zinc oxide at $500{ }^{\circ} \mathrm{C}$ and spectra show the reflectance edge at $375 \mathrm{~nm}, 373 \mathrm{~nm}$ and $377 \mathrm{~nm}$ for ZTA, ZCA and ZCTA samples, respectively. Kubelka-Munk function is used for the regeneration of the diffuse reflectance data into equivalent absorption coefficients $(\alpha)$ as materialized in Figure 3(b). Kubelka Munk function is given by Eq. No. 13. Spectra of zinc oxide show the absorption band at $360 \mathrm{~nm}$ for all samples and absorption edge at $388 \mathrm{~nm}, 394 \mathrm{~nm}$, and $396 \mathrm{~nm}$ for ZTA, ZCA and ZCTA samples, respectively.

$$
\mathrm{F}(\mathrm{RE})=(1-\mathrm{RE})^{2} / 2 \mathrm{RE}
$$

Where $R E$ is the reflectance data of the calcined sample and $F(R E)$ is Kubelka Munk function. The direct and indirect band gap of the prepared powder can be determined by using the Eq. No. 14 [22, $\underline{41}]$.

$$
(\mathrm{F}(\mathrm{RE}) \mathrm{hu})=\mathrm{D}\left(\mathrm{hu}-\mathrm{E}_{\mathrm{g}}\right)^{\mathrm{M}}
$$

Where $\mathrm{F}(R E)$ is Kubelka Munk function, $\mathrm{F}(h v)$ is energy function, $\mathrm{R}$ is the reflectance of the samples, $\mathrm{D}$ is constant and $\mathrm{M}$ is the value between $1 / 2$ and 2 based on the direct and indirect allowed electronic transitions, respectively [14]. The direct and indirect band gaps calculate by using the relation between $(\mathrm{F}(\mathrm{RE}) \mathrm{hv})^{1 / \mathrm{M}}$ and $(\mathrm{hv})$ as shown in Figure $4(\mathrm{a}-\mathrm{f})$. The values of direct (see Figure 5(a-c) and indirect (see Figure 4(d-f) band gaps are found to be 3.13-3.18 and 2.95-3.05 eV, respectively [12].

Fig. 3

Fig. 4

The photodegradation activity is controlled by the formation of the hydroxyl and superoxide anions radicals, obtained from the photogeneration action of photocatalysts for the starting of the photocatalysis reaction. The energy level of the synthesized zinc oxide can be controlled using the determined bandgap energy and the electronegativity. The conduction and 
valence bands of the fabricated zinc oxide nanoparticles at the point of zero charge can be determined utilizing the following Eq. No. 15-16.

$$
\begin{gathered}
E_{C B}+\frac{\mathrm{E}_{g}}{2}=\mathrm{X}+\mathrm{E}_{o} \\
E_{V B}-E_{g}=\mathrm{E}_{C B}
\end{gathered}
$$

Where $\mathrm{E}_{\mathrm{CB}}, \mathrm{E}_{\mathrm{VB}}, \mathrm{E}_{\mathrm{g}}, \mathrm{X}$ and $\mathrm{E}_{\mathrm{o}}$ are conduction band, valence band, band gap energy, the absolute electronegativity of zinc oxide, the reference electrode redox potential for the standard hydrogen electrode $(-4.5 \mathrm{eV})$, respectively $[\underline{7}, \underline{42}, \underline{43}]$. The values of band gap, conduction band and valence band are determined and summarized in Table 4.

Table 4

\subsection{Photocatalytic studies}

Photocatalytic activities of the synthesized ZnO nanoparticles (ZTA, ZCA and ZCTA samples) have been studied by testing the degradation of methyl orange (MO) and reactive red (RR195) dyes under UV- light. The intensity of the absorption bands of methyl orange (MO) and reactive red 195 (RR 195) dyes was recorded at $462 \mathrm{~nm}$ and $542 \mathrm{~nm}$, respectively. After one hour in dark, the adsorption percentage of methyl orange dye over the ZTA, ZCA, ZCTA is $14.5 \%, 17.6 \%$ and $11.9 \%$ respectively. Also, the adsorption capacity of reactive red dye over the ZTA, ZCA and ZCTA is $17.94 \%, 22.15 \%$ and $29.9 \%$, respectively. Fig. 5(a and b) displays the spectra data of the degradation of the reactive red (Fig. 5a) and methyl orange (Fig. 5b) dyes with time under UV- light.

Fig. 5(c and d) the relation between the degradation of reactive red 195 (RR 195) and methyl orange $(\mathrm{MO})$ dyes $\left(\mathrm{S}_{\mathrm{t}} / \mathrm{S}_{\mathrm{o}}\right)$ with irradiation time under the influence of UV illumination using ZTA, ZCA and ZCTA samples. The degradation of reactive red 195 (RR 195) dye was $94 \%, 93 \%$, and $91 \%$ after 70 min using ZTA, ZCA and ZCTA samples, respectively as shown in Fig. 4(c). From Figure 5(d), the degradation of methyl orange (MO) dye was 67.8, 57.55, and $70.57 \%$ after 300 min using ZTA, ZCA and ZCTA samples, respectively. According to Eq. No. 5, Figure 5(e and f) materialized the kinetic model in the form of the First order model of the degradation of methyl orange (MO) and reactive red 195 (RR195) dyes under UV-light over the synthesized ZTA, ZCA and ZCTA samples. Table 5 outlined the degradation percentage, $\mathrm{R}^{2}$ values and rate constant $\left(\mathrm{K}, \mathrm{min}^{-1}\right)$ of methyl orange (MO) and reactive red 195 (RR195) dyes under UV-light over the synthesized nanoparticles. The rate of degradation of RR195 dye over ZTA sample is faster than the other samples and photolysis of RR195 dye in 70 min (ZTA>ZCA>ZTCA). Besides, the degradation of MO dye on ZCTA sample is also faster than the other samples and photolysis of MO dye in 300 min (ZCTA>ZTA>ZCA). 
Figure 6( $a$ and $b$ ) displays the photodegradation of RR195 and MO dyes over ZTA sample and photolysis of the texting dyes in the presence of hydrogen peroxide. The degradation of RR195 dye over ZTA sample increased from $94 \%$ to $99.8 \%$ and the degradation time reduced from $70 \mathrm{~min}$ to $50 \mathrm{~min}$ in the presence of hydrogen peroxide as shown in Fig. 6(a). The rate degradation of RR195 dye over the fabricated ZTA sample in the presence of hydrogen peroxide is three time faster than that observed over the fabricated ZTA sample without hydrogen peroxide as displayed in Fig. 6(b). Also, the degradation of MO dye over ZTA sample increased from $68.8 \%$ to $95 \%$ and the degradation time reduced from $300 \mathrm{~min}$ to $70 \mathrm{~min}$ with $\mathrm{H}_{2} \mathrm{O}_{2}$ as shown in Fig. 6(a). The rate degradation of Mo dye over the fabricated ZTA sample with $\mathrm{H}_{2} \mathrm{O}_{2}$ is $\sim 13$ time faster than that observed over the fabricated ZTA sample without $\mathrm{H}_{2} \mathrm{O}_{2}$ as displayed in Fig. 6(b). Figure 7( $a$ and b) represented the effect of the synthesized zinc oxide nanoparticles (ZTA, ZCA, ZCTA samples) on the degradation of RR195 and MO dyes with and without the presence of hydrogen peroxide. The presence of hydrogen peroxide in the degradation of RR195 dye shows the activity in the raise of the values of degradation (from 91$94 \%$ to $99-99.8 \%$ ) and the reducing of the time of degradation from $70 \mathrm{~min}$ to $50 \mathrm{~min}$. Besides, the degradation of MO dye over the fabricated zinc oxide samples shows the increasing of the degradation values (from 57.55-70.57 \% to 81-95 \%) and the time of degradation reduced from $300 \mathrm{~min}$ to $70 \mathrm{~min}$.

\section{Table 5}

\subsection{Mechanism of photocatalysis}

The mechanism of photocatalytic degradation of the RR195 and MO dyes depends on the band gap of the synthesized catalyst (ZTA, ZCA, ZCTA samples). The fabricated zinc oxide catalyst can be catalytically active under UV light irradiation, according to the band gap of $\mathrm{ZnO}$ (3.13-3.18 eV). Under UV irradiation, the electrons excited and transfer to the conduction band from the valence band of zinc oxide nanoparticles (ZTA, ZCA, ZCTA samples), leading to the formation of holes in the valence band as shown in Scheme 2(a). The formation of superoxide radicals $\left(\dot{O}_{2}^{-}\right)$and hydroxyl radicals $\left({ }^{\circ} \mathrm{OH}\right)$ from the conduction (electrons) and valence (holes) bands, respectively. The formation of superoxide and hydroxyl radicals can be contributed for the decomposition of organic dyes over zinc oxide nanoparticles. The suggested mechanism of the degradation of the RR195 and MO dyes over the fabricated $\mathrm{ZnO}$ under UV irradiation are shown in Scheme 2(b).

\section{Scheme 2}




\subsection{Comparison of photodegradation of RR195 and MO dyes with other catalysts}

The photodegradation of RR195 and MO dyes over the fabricated zinc oxide nanoparticles has been compared with other catalysts reported in the literature as shown in Table 6 . The tabulated data show that the catalyst type, degradation percentage, time, and the other conditions for the photodegradation of RR195 and MO dyes [44-56].

Table 6

\section{Conclusions}

A new fabrication method for the preparation of zinc oxide nanoparticles was done using auto-combustion method using zinc nitrate as an oxidizer and fuels (citric acid, tartaric acid, and a mixture of them) following by the calcination at $500{ }^{\circ} \mathrm{C}$. The obtained zinc oxide nanoparticles were characterized by different tools like XRD, DRS, FT-IR, and HR-TEM. The XRD pattern of calcined zinc oxide shows the characteristic lines of hexagonal phase with an average crystallite size of 24-39 $\mathrm{nm}$. The direct band gap of the synthesized ZTA, ZCA and ZCTA samples were determined and found to be 3.18, 3.15 and $3.13 \mathrm{eV}$, respectively. The HRTEM micrograph of the obtained zinc oxide sample reveals the spherical and hexagonal shape with hard agglomeration and the average particle size calculated from TEM-image is about 52 $\mathrm{nm}$. The characteristic absorption peaks appeared in the range of $425-430 \mathrm{~cm}^{-1}$, indicates the stretching vibration mode of $\mathrm{Zn}-\mathrm{O}$ inside the crystal lattice of zinc oxide. The values of the lattice parameters (a and c), the ratio (c/a), unit cell volume (V) and $\mathrm{Zn}-\mathrm{O}$ bond length (L) were determined and found in the range of 3.2333-3.2490 A, 5.1935-5.2081 A and 1.60251-1.60423, 47.2594-47.5458 $\mathrm{A}^{3}$ and 1.9727-1.9767 A, respectively. The calculated values are near to the standard value for hexagonal phase of zinc oxide. The degradation values of reactive red 195 and methyl orange dyes over the synthesized zinc oxide (ZTA, ZCA and ZCTA samples) recorded 91-94 \% 57.55-70.57\% after $70 \mathrm{~min}$ and $300 \mathrm{~min}$ under the influence of UV irradiation, respectively. The degradation values increased to be 99-99.8 \% 81-95\% after the addition of $\mathrm{H}_{2} \mathrm{O}_{2}$ in $50 \mathrm{~min}$ and $70 \mathrm{~min}$, respectively under UV irradiation. Also, the mechanism of the photodegradation was successfully suggested.

\section{Acknowledgements}

The authors express their thanks to Benha University, Benha, Egypt for support of the current research.

\section{References}

[1] O.M. El-Feky, E.A. Hassan, S.M. Fadel, M.L. Hassan, J. Cult. Heritage 15, 165 (2014)

[2] J. Salla, K.K. Pandey, K. Srinivas, Polym Degrad Stab 97, 592 (2012) 
[3] S. Kakarndee, S. Nanan, J. Environ. Chem. Eng. 6, 74 (2018)

[4] R. Saravanan, D. Manoj, J. Qin, M. Naushad, F. Gracia, A.F. Lee, M.M. Khan, M.A. GraciaPinilla, Process Saf. Environ. Prot. 120, 339 (2018)

[5] A.A. Ali, S.R. El-Sayed, S.A. Shama, T.Y. Mohamed, A.S. Amin, Desalin. Water Treat. 204, $124(2020)$

[6] A.A. Ali, I.S. Ahmed, E.M. Elfiky, J Inorg Organomet Polym 31, 384 (2021)

[7] M.Y. Nassar, A.A. Ali, A.S. Amin, RSC Adv. 7, 30411 (2017)

[8] Y. Yang, H. Chen, B. Zhao, X. Bao, J Cryst Growth 263, 447 (2004)

[9] I. Kontopoulou, A. Angelopoulou, N. Bouropoulos, Mater Lett 165, 87 (2016)

[10] S. Baskoutas, P. Giabouranis, S.N. Yannopoulos, V. Dracopoulos, L. Toth, A. Chrissanthopoulos, N. Bouropoulos, Thin Solid Films 515, 8461 (2007)

[11] S. Bazazi, N. Arsalani, A. Khataee, A.G. Tabrizi, J. Ind. Eng. Chem. 62, 265 (2018)

[12] T. Chankhanittha, S. Nanan, Mater Lett 226, 79 (2018)

[13] M.Y. Nava Núñez, A. Martínez-de la Cruz, Mater Sci Semicond Process 81, 94 (2018)

[14] A.K. Zak, M.E. Abrishami, W.A. Majid, R. Yousefi, S. Hosseini, Ceram Int 37, 393 (2011)

[15] R. Bekkari, L. laânab, D. Boyer, R. Mahiou, B. Jaber, Mater Sci Semicond Process 71, $181(2017)$

[16] R. Mahdavi, S.S. Ashraf Talesh, Ultrason Sonochem 39, 504 (2017)

[17] D. Raoufi, Renewable Energy 50, 932 (2013)

[18] A.S. Lanje, S.J. Sharma, R.S. Ningthoujam, J.-S. Ahn, R.B. Pode, Adv Powder Technol $24,331(2013)$

[19] C. Chen, P. Liu, C. Lu, Chem Eng J 144, 509 (2008)

[20] Y. Ni, X. Cao, G. Wu, G. Hu, Z. Yang, X. Wei, Nanotechnology 18, 155603 (2007)

[21] S. Goutham, S. Kaur, K.K. Sadasivuni, J.K. Bal, N. Jayarambabu, D.S. Kumar, K.V. Rao, Mater Sci Semicond Process 57, 110 (2017)

[22] A.A. Ali, E. El Fadaly, I.S. Ahmed, Dyes Pigm. 158, 451 (2018)

[23] R. Al-Gaashani, S. Radiman, A. Daud, N. Tabet, Y. Al-Douri, Ceram Int 39, 2283 (2013)

[24] L.C. Nehru, V. Swaminathan, C. Sanjeeviraja, Powder Technol 226, 29 (2012)

[25] M. Hasanpoor, M. Aliofkhazraei, H. Delavari, Procedia Mater. Sci. 11, 320 (2015)

[26] M.R. Hoffmann, S.T. Martin, W. Choi, D.W. Bahnemann, Chem Rev 95, 69 (1995)

[27] M. Driessen, T. Miller, V. Grassian, J Mol Catal A: Chem 131, 149 (1998)

[28] K.G. Chandrappa, T.V. Venkatesha, Nano-Micro Lett. 4, 14 (2012)

[29] J. Iqbal, T. Jan, Y. Ronghai, S.H. Naqvi, I. Ahmad, Nano-Micro Lett. 6, 242 (2014)

[30] A.H. Abdullah, L.K. Mun, Z. Zainal, M.Z. Hussein, Int. J. Chem. 5, 56 (2013) 
[31] S. Singh, M. Joshi, P. Panthari, B. Malhotra, A.C. Kharkwal, H. Kharkwal, Nano-Struct. Nano-Objects 11, 1 (2017)

[32] T. Charinpanitkul, K. Faungnawakij, W. Tanthapanichakoon, Adv Powder Technol 19, $443(2008)$

[33] S.D. Lee, S.-H. Nam, M.-H. Kim, J.-H. Boo, Physics Procedia 32, 320 (2012)

[34] K.S. Babu, A.R. Reddy, C. Sujatha, K.V. Reddy, Mater Lett 99, 97 (2013)

[35] C.S. Rout, A. Raju, A. Govindaraj, C. Rao, Solid State Commun 138, 136 (2006)

[36] I. Ahmed, H. Dessouki, A. Ali, Spectrochim. Acta, Part A 71, 616 (2008)

[37] A.A. Ali, E.M. Elfiky, I.S. Ahmed, A.A. Khalil, T.Y. Mohamed, Desalin. Water Treat. $193,83(2020)$

[38] M.A. Gabal, F. Al-Solami, Y.M. Al Angari, A. Awad, A.A. Al-Juaid, A. Saeed, J Mater Sci - Mater Electron 31, 3146 (2020)

[39] U. Seetawan, S. Jugsujinda, T. Seetawan, A. Ratchasin, C. Euvananont, C. Junin, C. Thanachayanont, P. Chainaronk, Mater. Sci. Appl. 2, 1302 (2011)

[40] A. Sahai, N. Goswami, Physica E 58, 130 (2014)

[41] A.A. Ali, I.S. Ahmed, Mater Chem Phys 238, 121888 (2019)

[42] Y. Zhang, R. Mandal, D.C. Ratchford, R. Anthony, J.J.N. Yeom, J. Nanomater. 10, 491 (2020)

[43] R.G. Pearson, J Inorg. Chem. 27, 734 (1988)

[44] R. Kumar, G. Kumar, A. Umar, Mater Lett 97, 100 (2013)

[45] T.A. Saleh, V.K. Gupta, J Colloid Interface Sci 371, 101 (2012)

[46] Y. Li, X. Li, J. Li, J. Yin, Water Res 40, 1119 (2006)

[47] Z. Vaez, V. Javanbakht, J. Photochem. Photobiol., A 388, 112064 (2020)

[48] H. Lahmar, M. Benamira, S. Douafer, L. Messaadia, A. Boudjerda, M. Trari, Chem Phys Lett 742, 137132 (2020)

[49] N. Li, Y.-1. He, Z.-z. Yi, L. Gao, F.-r. Zhai, K. Chattopadhyay, Ceram Int 46, 19038 (2020)

[50] A. Krishnan, P.V. Vishwanathan, A.C. Mohan, R. Panchami, S. Viswanath, A.V.

Krishnan, Surf. Interfaces 22, 100808 (2021)

[51] S. Narendhran, P.B. Shakila, M. Manikandan, V. Vinoth, P. Rajiv, Spectrochim. Acta, Part A 232, $118164(2020)$

[52] M.H. Habibi, Z. Rezvani, Spectrochim. Acta, Part A 147, 173 (2015)

[53] X.N. Pham, H.T. Nguyen, T.N. Pham, T.T.-B. Nguyen, M.B. Nguyen, V.T.-T. Tran, H.V. Doan, J. Taiwan Inst. Chem. Eng. 114, 91 (2020) 
[54] C.A.A. Pereira, M.R. Nava, J.B. Walter, C.E. Scherer, A. Dominique Kupfer Dalfovo, M.

Barreto-Rodrigues, J Hazard Mater 401, 123275 (2021)

[55] Y. Dong, P. Wang, B. Li, J. Cleaner Prod. 208, 1347 (2019)

[56] M.H. Karaoğlu, M. Uğurlu, J Hazard Mater 174, 864 (2010) 
Figures
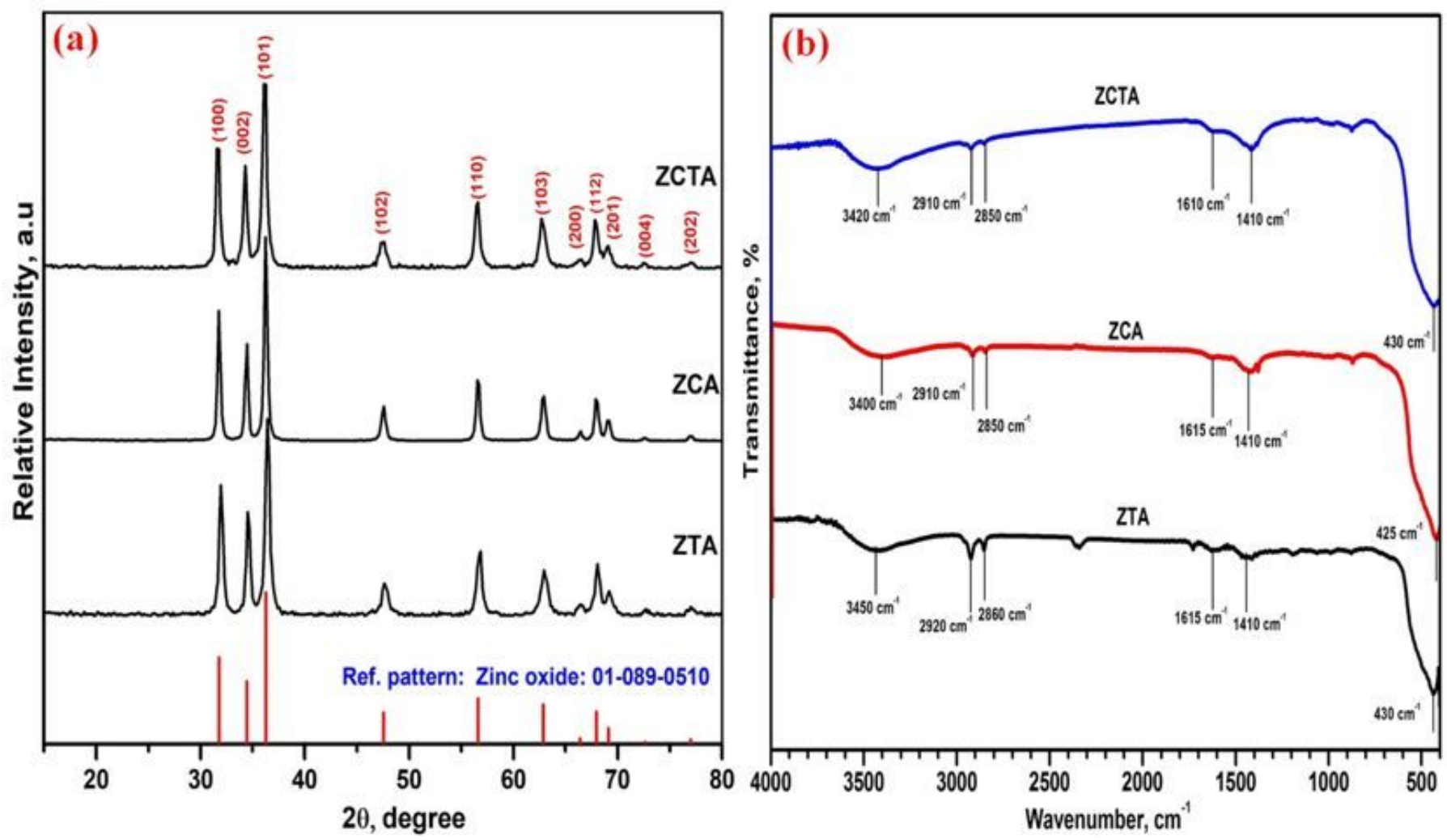

Figure 1

XRD patterns (a) and FTIR spectra (b) of zinc oxide nanoparticles (ZTA, ZCA and ZCTA samples) after calcination at 500 oC for $2 \mathrm{~h}$. 


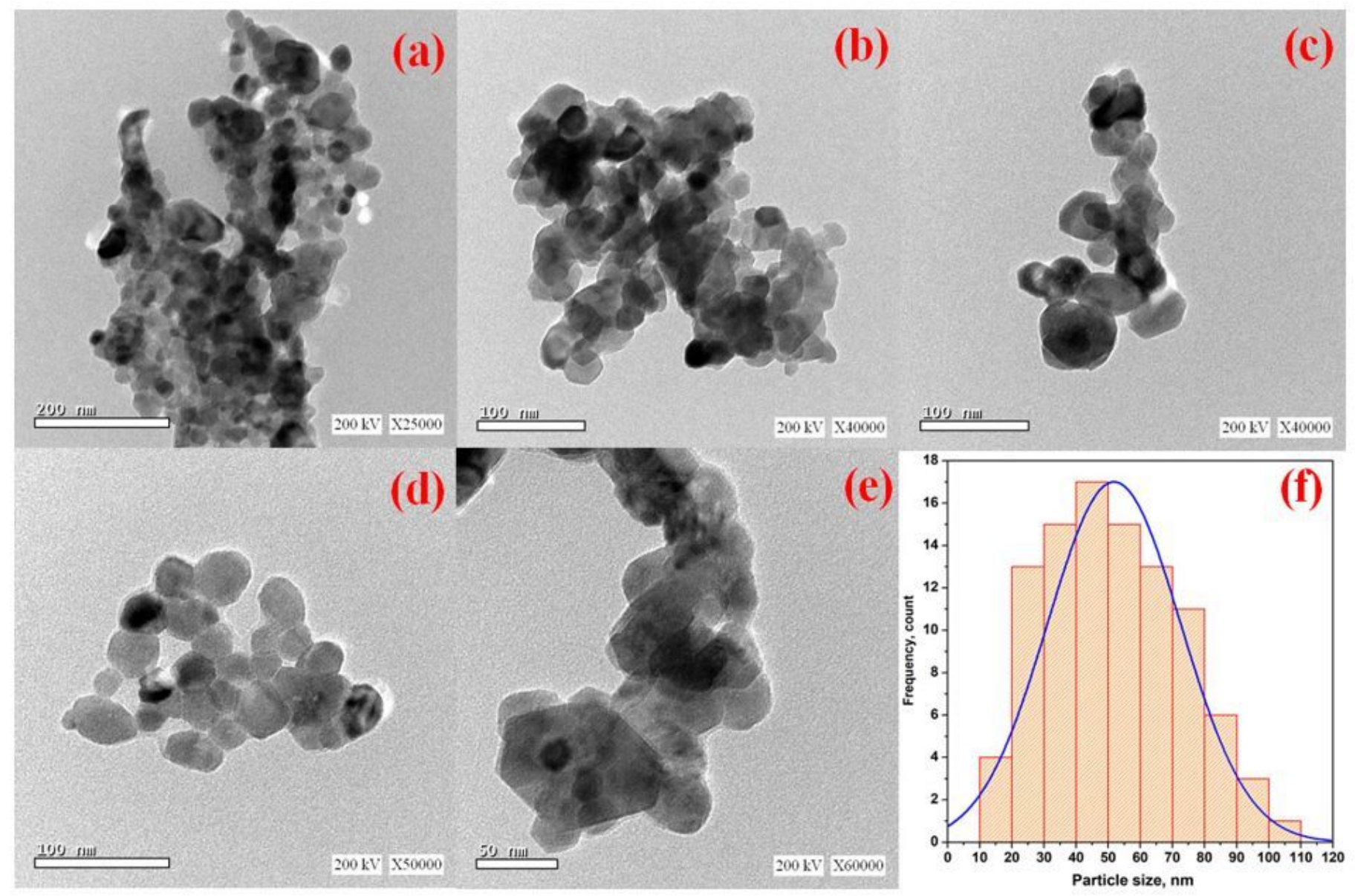

Figure 2

HR-TEM micrographs (a-e) and) and histogram graph for TEM images of the synthesized zinc oxide nanoparticles (ZTA sample) after calcination at $500 \mathrm{oC}$. 

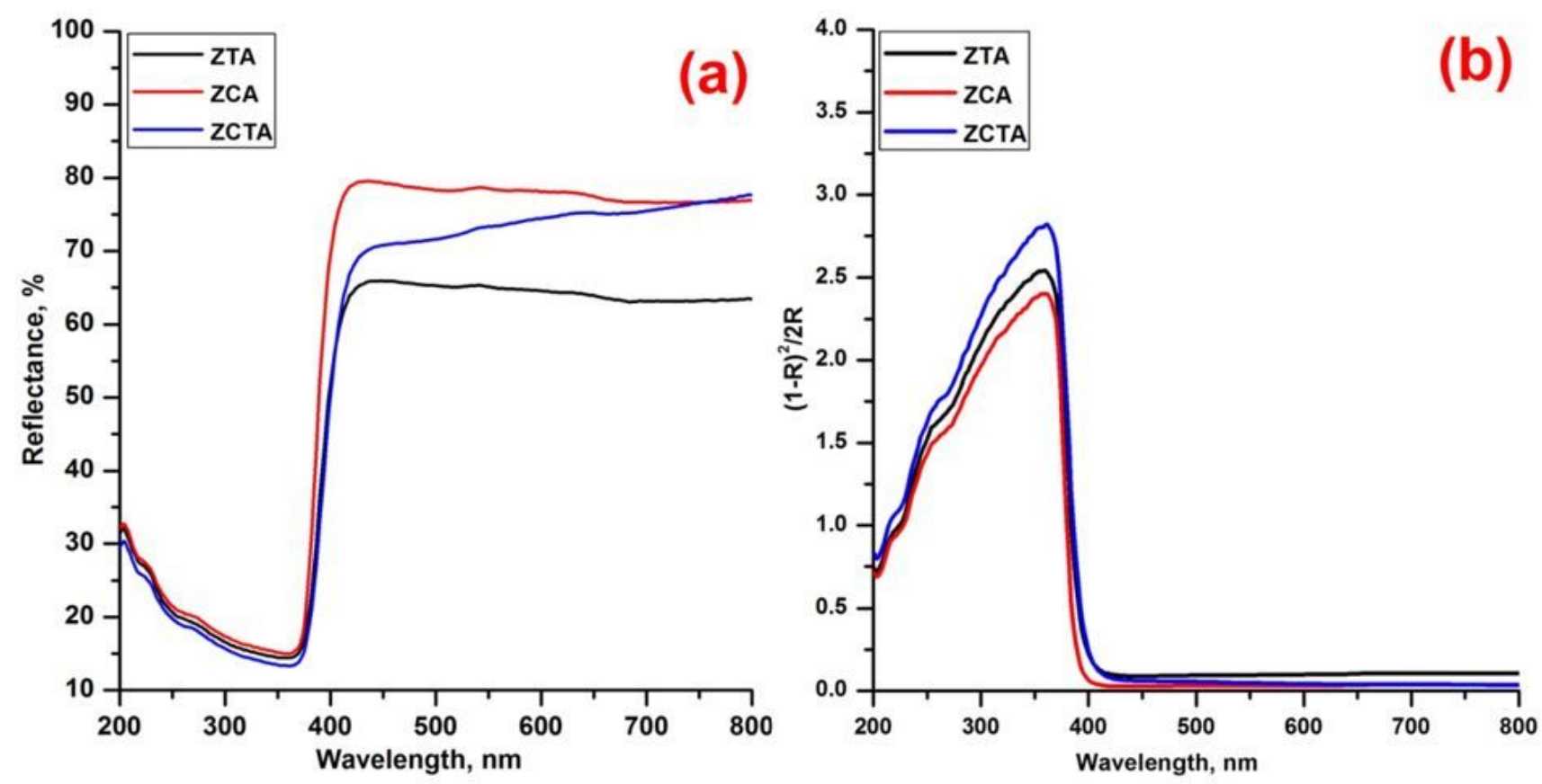

Figure 3

(a) UV-Vis diffuse reflectance spectra, (b) UV-Vis absorption spectra of the ZnO samples after calcination at 500 oC. 

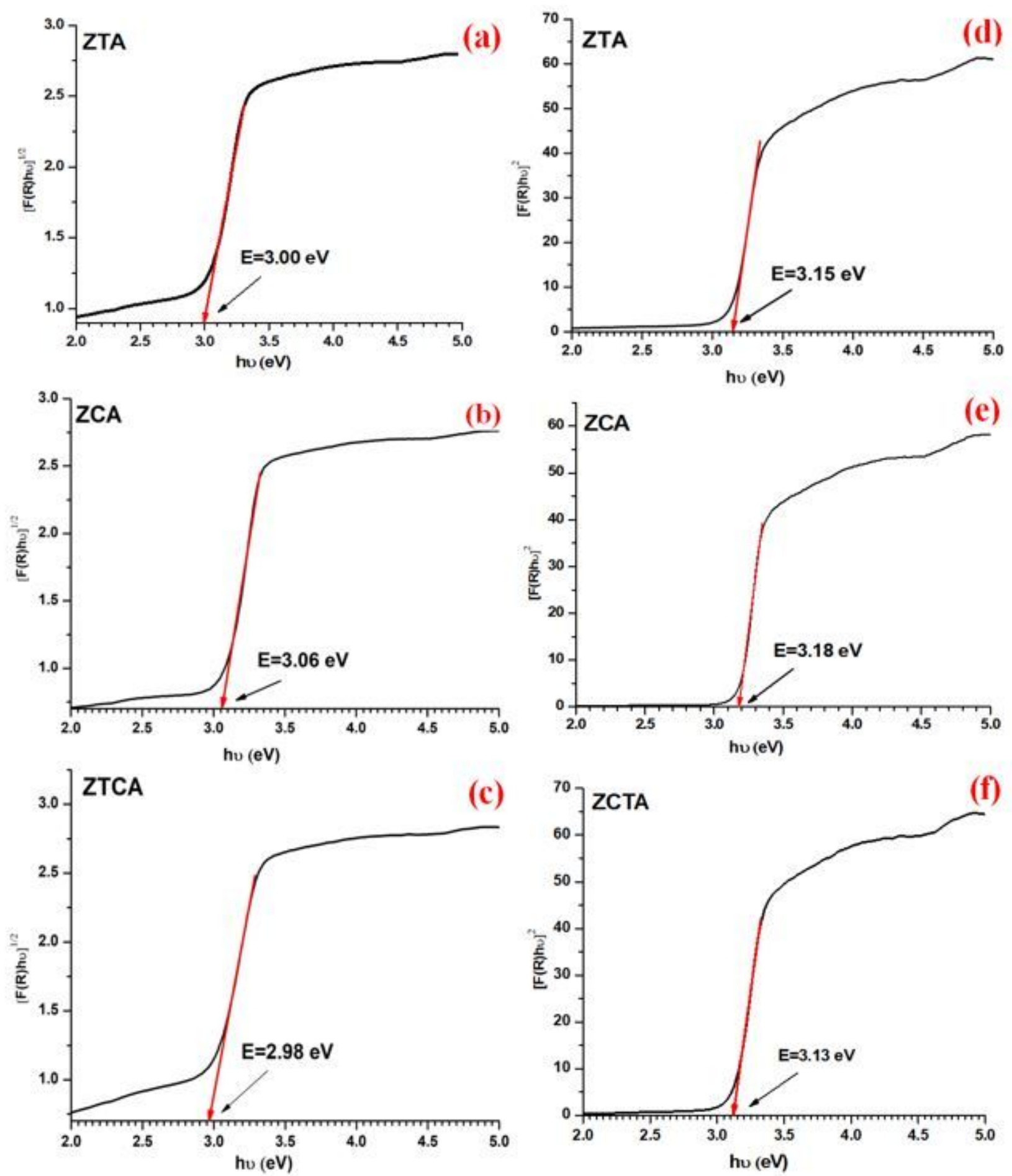

Figure 4

The optical studies for the calcined zinc oxide nanoparticles: indirect band gap calculation $(a, b$ and $c)$ and direct band gap calculation (d, e and f). 

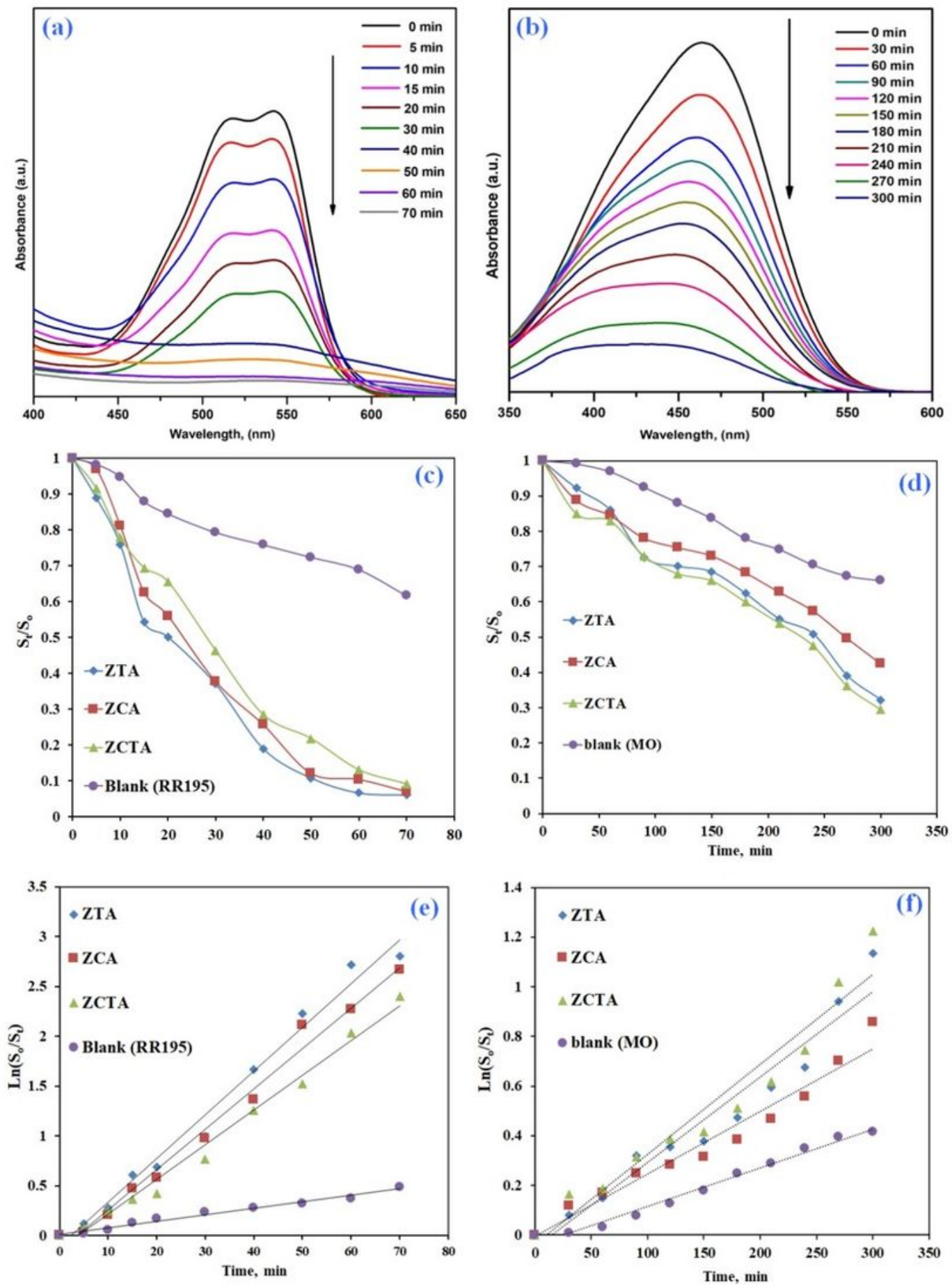

\section{Figure 5}

Spectra ( $a$ and b), photocatalytic degradation ( $c$ and d) and kinetic (e and f) of the reactive red ( $a$, $c$ and e) and methyl orange ( $b, d$ and $f$ ) dyes over the synthesized zinc oxide nanoparticles (ZTA, ZCA and ZCTA samples). 

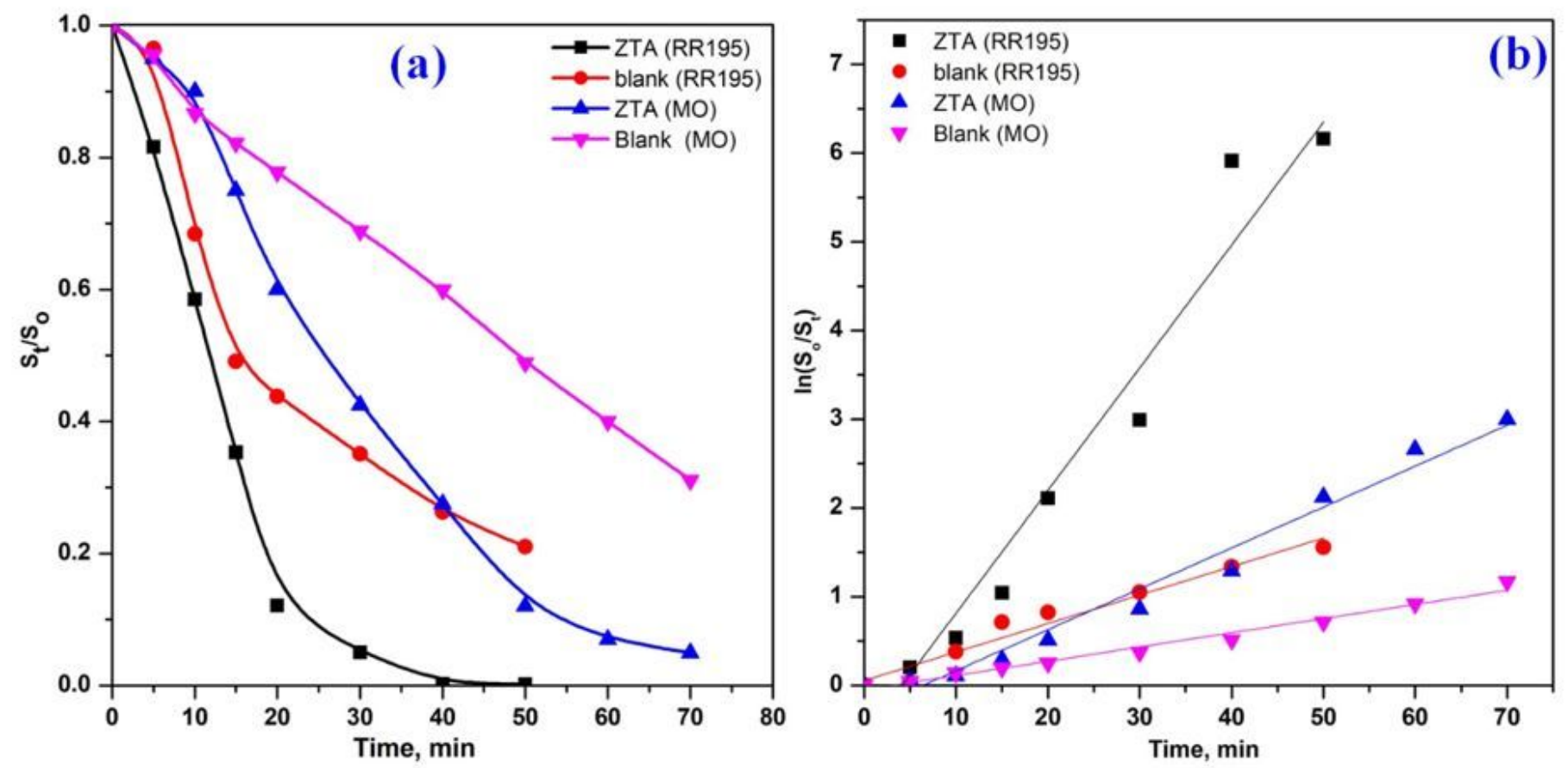

Figure 6

Effect of hydrogen peroxoide on the photocatalytic degradation (a), kinetic of the reactive red (RR195) and methyl orange (MO) dyes over the synthesized zinc oxide nanoparticles (ZTA sample).
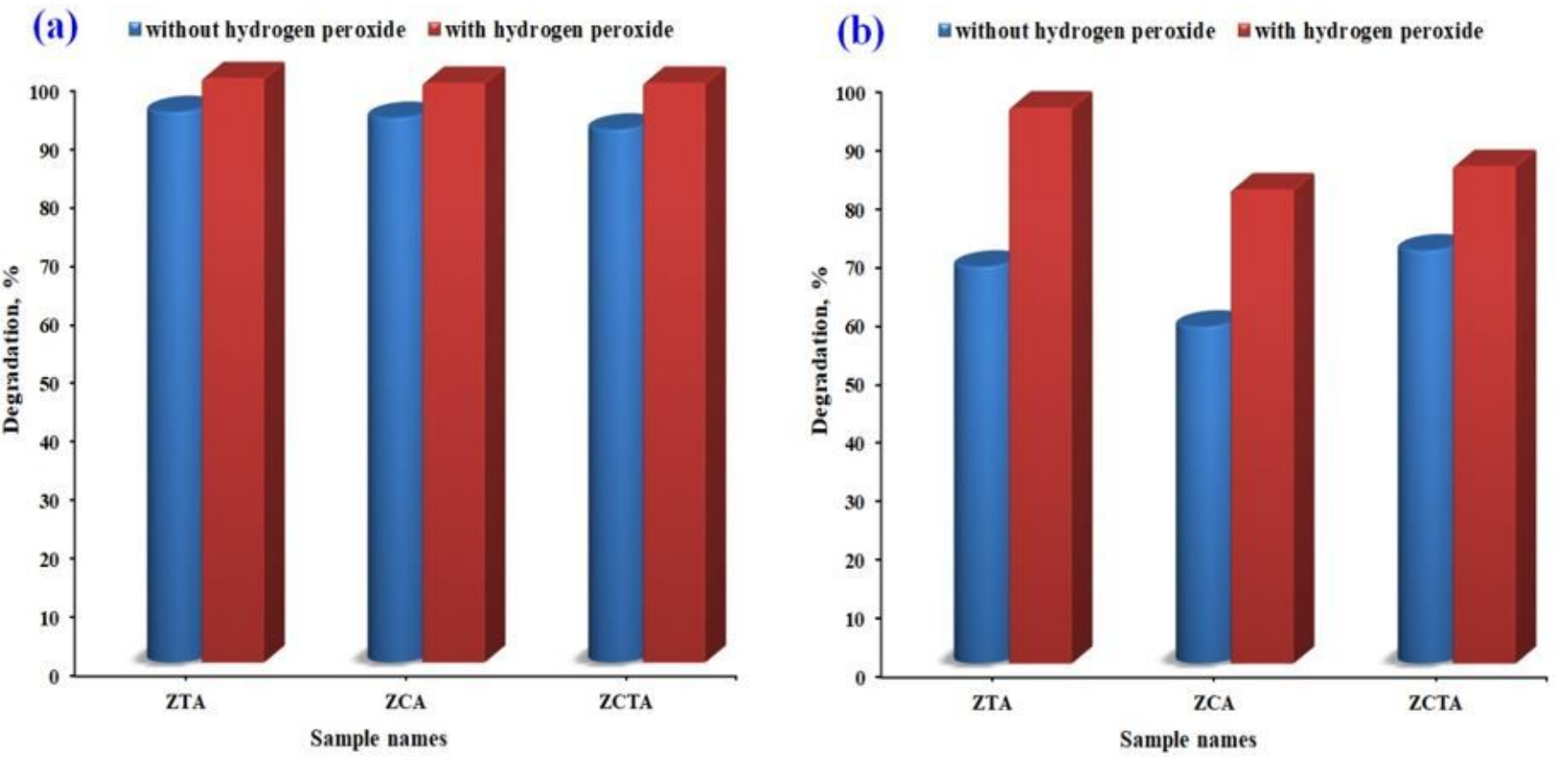

Figure 7

Degradation of a) the reactive red (RR195) and b) methyl orange (MO) dyes with and without the presence of hydrogen peroxide. 


\section{Supplementary Files}

This is a list of supplementary files associated with this preprint. Click to download.

- Scheme2.jpg

- Scheme1.jpg 